\title{
THE USE OF GROSS EFFICIENCY COEFFICIENTS IN CYCLISTS' ENDURANCE TESTS
}

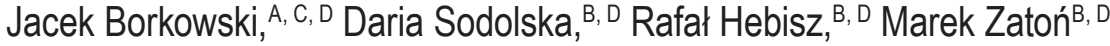 \\ Department of Physiology and Biochemistry, University School of Physical Education, Wrocław, Poland \\ ${ }^{\text {A }}$ Study Design; ${ }^{\mathrm{B}}$ Data Collection; ${ }^{\mathrm{C}}$ Statistical Analysis; ${ }^{\mathrm{D}}$ Manuscript Preparation \\ Address for coprespondence: \\ Jacek Borkowski \\ University School of Physical Education, Department of Physiology and Biochemistry \\ Paderewskiego Avenue 35, 51-612 Wrocław, Poland \\ E-mail: jacek.borkowski@awf.wroc.pl
}

\begin{abstract}
Ahstract. The efficiency of energy conversion of aerobic metabolism to external work is of great importance to sports exercise. Despite this fact, gross efficiency (GE) is not commonly used as a parameter in the assessment of cyclists' exercise ability. It is also known that road cyclists traverse most of their route at a work intensity below the anaerobic threshold (AT). We tried to examine the relationship between the standard aerobic parameters used for defining the endurance of cyclists and GE, measured just below the anaerobic threshold. Fifty cyclists were subjected to a progressive test. Work done and the basic respiratory and circulatory parameters were measured. Gross efficiency was calculated at work intensity just below AT. We observed a very low correlation $(R=-0.137)$ between GE $(24.9 \pm 2.06)$ and maximal oxygen uptake $\left(\mathrm{VO}_{2} \mathrm{max}\right)-63.8 \pm 6,27 \mathrm{ml} \times \mathrm{kg}^{-1} \times \mathrm{min}^{-1}$. The strongest correlation $(\mathrm{R}=-0.258)$ was recorded between GE and the percentage of maximal oxygen consumption $(58.9 \pm 7.0 \%)$ for the load prior to the occurrence of the anaerobic threshold. The weak, but existing correlation between GE and selected respiratory and circulatory parameters may suggest that GE provides unique and independent information about the examined athletes.
\end{abstract}

Key WOrlls: gross efficiency; cycling; anaerobic threshold

\section{Introduction}

Physiologists and trainers have long been interested in work efficiency (Gaesser and Brooks 1975). Moreover, there are articles in the scientific literature describing the gross efficiency (GE) coefficient in research on adaptation to effort. These studies, however, do not provide clear results. The variability of this parameter during a season (Hopker et al. 2010) and the dependence of this parameter on the diet in the days before the test (Dumke et al. 2007) have been observed. Work efficiency is defined as the ratio of external work done to the energy released in the metabolism necessary to ensure that external work could be done. Work efficiency is not a commonly used parameter in endurance tests. This is strange, because it seems that work done at a lower energetic cost should facilitate success in sport. During work at constant submaximal intensity, $\mathrm{O}_{2}$ consumption is proportional to the load. 
During the test, oxygen consumption increases progressively as the load increases. Using this relationship, work efficiency can be calculated by the following formula at any given moment (Herman 2007):

$$
\text { Efficiency }=\frac{\Delta \text { intensity }}{\Delta \mathrm{VO}_{2} \times \text { caloric coefficient }} .
$$

The way of calculating work efficiency is to use the conversion factors using oxygen consumption and taking the $R Q$ coefficient into account. These conversion ratios were determined by Zunz in 1901 (McArdle et al. 2006). This method has its limitations. At more intensive work, the substantial part of adenosine triphosphate (ATP) used for performing muscle functions comes from anaerobic metabolism. To date it has been extremely difficult to properly estimate the share of anaerobic metabolism in bioenergetics. However, there are some works in which such attempts have been described (de Koning et al. 2013). It is a well-known fact that good cyclists have a high maximal oxygen uptake, as well as high oxygen uptake at the anaerobic threshold, high power at the anaerobic threshold (AT) and maximal aerobic power achieved in progressive tests. It is also known that road cyclists traverse most of the route at a work intensity of less than AT.

The aim of this study is to examine the relationship between the standard parameters used for defining the endurance of cyclists and the GE, measured just below the anaerobic threshold.

\section{Materials and methods}

The study included 50 cyclists performing progressive tests on a cycle ergometer in the Laboratory of Exercise (ISO 9001 Certificate) at the Department of Physiology and Biochemistry, University School of Physical Education in Wroclaw. The tests were performed over the years 2005-2014, and were carried out at the request of the cyclists and their sports clubs. Both the examined subjects and their clubs provided written permission for their results to be used in scientific studies.

The most important data characterizing the cyclists surveyed are shown in Table 1.

Table 1. Basic anthropological data and maximal oxygen consumption of examined cyclists

\begin{tabular}{lcccc}
\hline & Age & Body mass & Body height & $\mathrm{VO}_{2} \mathrm{max}$ \\
{$[$ [years] } & {$[\mathrm{kg}]$} & {$[\mathrm{mm}]$} & $6 \mathrm{~kg}]$ \\
\hline Mean & 19.50 & 68.40 & 178.20 & 63.80 \\
SD & 2.80 & 5.28 & 5.18 & 6.27 \\
\hline
\end{tabular}

The height and weight of cyclists were measured using the Radwag tool before starting the exercise test. First, the subjects sat on an ergometer and remained at rest for 3 minutes. At this point, pre-exercise oxygen consumption was measured. Progressive tests were performed, without a prior warm-up, on the Monark cycle ergometer or on Excalibour, a product of Lode. The progressive tests started from a load of $50 \mathrm{~W}$. Participants used a cadence of about 80-90 revolutions per minute. The load was increased every three minutes by $50 \mathrm{~W}$, to the point where the subject could not keep up with the imposed work intensity. During the test and the subsequent 5 minutes the following parameters were recorded: oxygen consumption, $\mathrm{CO}_{2}$ excretion and ventilation using k4b2 device. Simultaneously, participants' heart rates were recorded using a heart rate monitor produced by Polar. Maximal 
oxygen uptake and anaerobic threshold were measured and calculated using a k4b2 device and computer program of the same name. The anaerobic threshold was measured indirectly through the determination of a ventilatory threshold (Beaver et al. 1986). A work efficiency ratio was calculated for the load, prior to the occurrence of the anaerobic threshold.

In calculating the efficiency ratio, two assumptions were made:

1. It is assumed that at this point of the test, the whole energy is coming from the oxidation of carbohydrates muscle glycogen and glucose. The subjects had the respiratory exchange ratio (RER) very close to 1 at the load immediately preceding the anaerobic threshold. Moreover, according to the literature, the acceleration of fatty acid oxidation in the first few minutes of exercise is insignificant. The energy equivalent of oxygen at $21.14 \mathrm{~kJ} / \mathrm{I} \mathrm{O}_{2}$ was assumed.

2. The oxygen consumption which was used in our calculations was measured at the last minute of the test load prior to the occurrence of AT, but decreased by the value of oxygen consumption before the workload. The moment of measurement was chosen individually for each test record. An example of chosen moments of oxygen consumption measurements for a participant is shown in Figure 1.

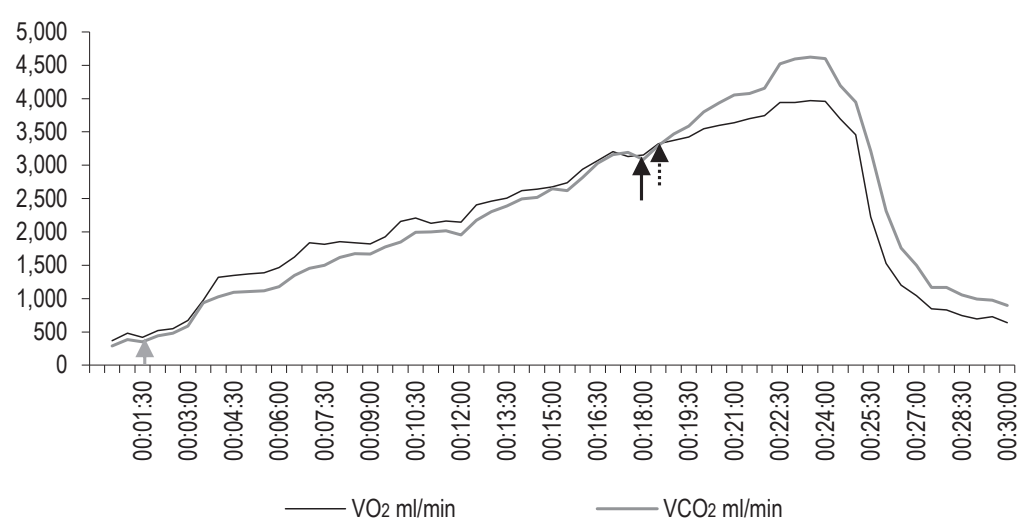

Figure 1. Example of a progressive test with marked points: resting oxygen uptake (grey arrow), oxygen uptake representing the determined GE (black arrow), oxygen uptake at AT (dotted arrow)

To calculate the gross coefficient, the following formula was used (Geasser and Brooks 1975):

$G E=\frac{\text { Work done in one minute at load before the AT }[\mathrm{k}]]}{\text { (oxygen consumption at load before the AT[L] - oxygen consumption without load }[\mathrm{L}] \times 21.14(\mathrm{kj} / \mathrm{L})}$

A statistical analysis of the results was conducted using Excel (MS Office). 


\section{Results}

The results of the analysis of respiratory gases and heart rate are shown in Table 2.

Table 2. Chosen respiratory and circulatory parameters of the examined cyclists

\begin{tabular}{lcccccc}
\hline Parameter & $\begin{array}{c}\text { Oxygen uptake } \\
\text { without load } \mathrm{VO}_{2} \\
{[\mathrm{ml}]}\end{array}$ & $\begin{array}{c}\text { Maximal Oxygen } \\
\text { uptake } \mathrm{VO}_{2} \\
{[\mathrm{ml}]}\end{array}$ & $\begin{array}{c}\mathrm{VO}_{2} \text { max } \\
{[\mathrm{ml} / \mathrm{kg}]}\end{array}$ & $\begin{array}{c}\mathrm{VO}_{2} \text { at anaerobic } \\
\text { threshold } \\
{[\mathrm{ml} / \mathrm{kg}]}\end{array}$ & $\begin{array}{c}\%^{2} \mathrm{VO}_{2} \text { max } \\
\text { at anaerobic } \\
\text { threshold }\end{array}$ & $\begin{array}{c}\text { Heart rate } \\
\text { at anaerobic } \\
\text { threshold } \\
{[\mathrm{b} / \mathrm{min}]}\end{array}$ \\
\hline Mean & 371.66 & 4352.38 & 63.80 & 48.73 & 77.22 & 165.48 \\
SD & \pm 89.60 & \pm 433.12 & \pm 6.27 & \pm 5.35 & \pm 5.78 & \pm 11.36 \\
\hline
\end{tabular}

Respiratory, load and work efficiency parameters are given in Table 3.

Tahle 3. Load, work and respiratory parameters of examined cyclists

\begin{tabular}{lcccccc}
\hline Parameter & $\begin{array}{c}\text { Load before AT } \\
{[\mathrm{W}]}\end{array}$ & $\begin{array}{c}\mathrm{VO}_{2} \text { before AT } \\
{[\mathrm{ml}]}\end{array}$ & $\begin{array}{c}\mathrm{Net} \mathrm{VO}_{2} \text { before AT } \\
{[\mathrm{ml}]}\end{array}$ & $\begin{array}{c}\text { Energy } \\
\text { calculated } \\
{[\mathrm{kJ}]}\end{array}$ & $\begin{array}{c}\text { Work measured } \\
{[\mathrm{kJ}]}\end{array}$ & $\begin{array}{c}\text { Work efficiency } \\
{[\%]}\end{array}$ \\
\hline Mean & 227.00 & 2970.61 & 2598.95 & 54.94 & 13.62 & 24.90 \\
SD & 30.66 & 365.33 & 359.10 & 7.59 & 1.84 & 2.06 \\
\hline
\end{tabular}

The correlation coefficient between the $\mathrm{VO}_{2}$ max and gross efficiency was calculated. This relation was weak: $R=-0.137$.

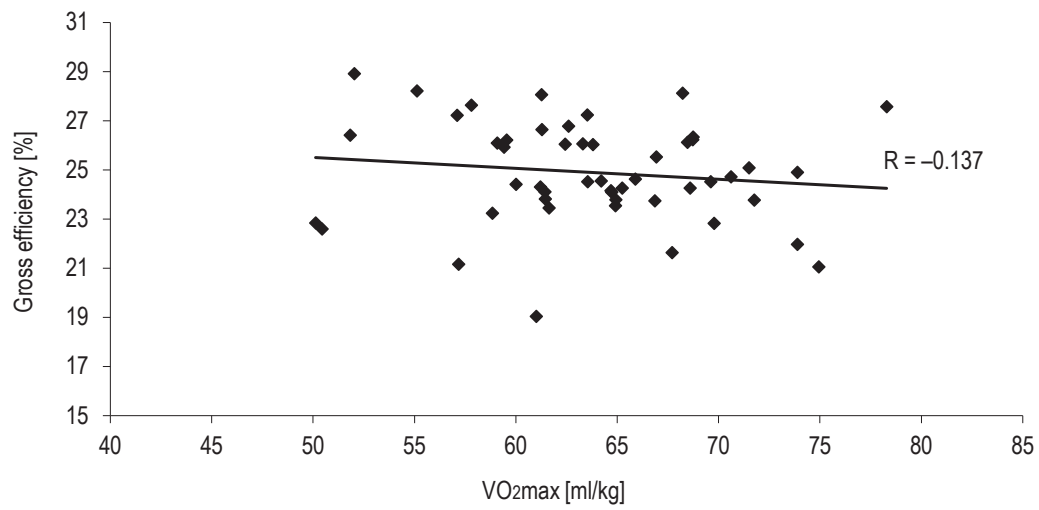

Figure 2. The relationship between $\mathrm{VO}_{2}$ max and gross efficiency in examined cyclists 
The correlation coefficient between the percentage of $\mathrm{VO}_{2}$ max on the last load before AT and gross efficiency was also calculated. It was found that the compound is low, as $R=-0.258$. See Figure 3 .

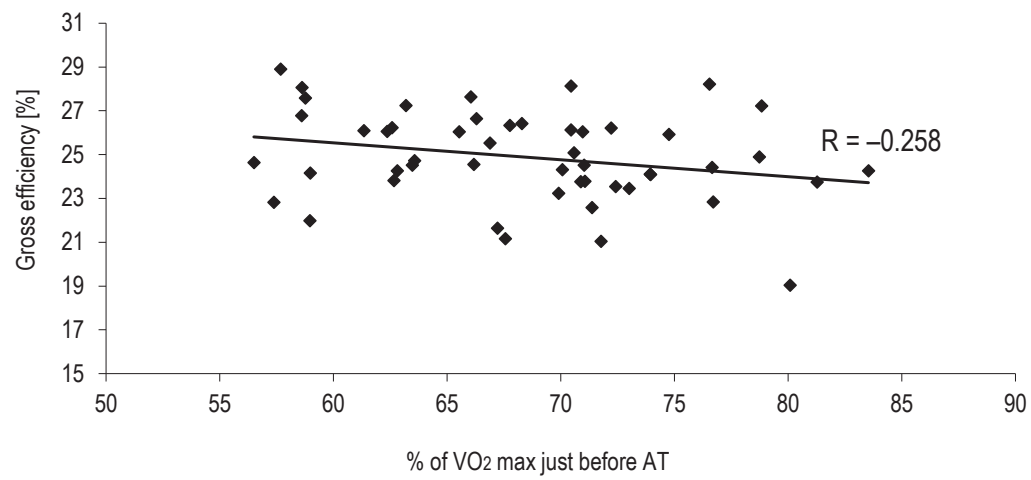

Figulp 3. The relationship between $\%$ of $\mathrm{VO}_{2} \max$ ( $\mathrm{ml} / \mathrm{kg}$ of body mass) measured on the last load before AT and gross efficiency in cyclists tested

Values of Pearson correlation coefficients for other physiological parameters and work efficiency were also calculated. All tested features were proven to be unrelated to GE. The results are shown in Table 4.

Tahle 4. The correlation coefficient between gross efficiency and chosen physiological parameters

\begin{tabular}{cccc}
\hline Feature & HR on AT & $\% \mathrm{VO}_{2}$ max on AT & Oxygen uptake without load \\
\hline Pearson correlation to GE & 0.037 & -0.054 & -0.019 \\
\hline
\end{tabular}

\section{Discussion}

Road cycling is considered as endurance competition. Cycling races sometimes take several days, or many hours in the case of an individual stage or single race. As such, the economization of work is a very important factor that may determine the level of success in a race. Therefore, long-lasting work must be performed mostly with an intensity below the anaerobic threshold. Performing the work with such intensity allows the cyclist to overcome the majority of the distance, as well as to regenerate during the race after more intensive parts of the stage. Success in cycling comprises many factors, some of which are of interest to physiology. Parameters such as $\mathrm{VO}_{2}$ max, metabolic thresholds and maximum power demonstrate physical preparation for competition. Particularly important is the determination of these parameters among young athletes, as they have prognostic significance in the selection of competitors, particularly $\mathrm{VO}_{2} \max$ (Zaton et al. 2011). The issue of work efficiency is one that hitherto has not been widely addressed in the scientific literature. GE reflects the degree to which energy derived from aerobic metabolism appears in the form of external work. It can therefore be assumed that when GE is greater, 
better results can be achieved during the competition. According to Moseley et al. (2004), world-class cyclists do not show higher work efficiency on an ergometer than amateurs. From this point of view, it can be assumed that this parameter is not particularly useful in the assessment of physical fitness. There are articles describing that the GE value varies in a given cyclist, and even changes in reverse proportion to changes in $\mathrm{VO}_{2} \mathrm{max}$. $(\mathrm{Hopker}$ et al. 2012). On the other hand, the findings of Hopker et al. (2010) suggest that intensive training improves gross efficiency. Studies of members of the same team showed that GE is higher in women than in men in cases of the same absolute intensities of work (Hopker et al. 2010). It was also found that GE is also affected by changes in diet. An increase in GE was noted when participants followed a 3-day high carbohydrate diet before the endurance test (Cole et al. 2014). Leirdal and Ettema (2011) found that an increase in pedaling frequency causes a loss of work efficiency at an intensity of $75 \% \mathrm{VO}_{2}$ max, while Abbiss and Laursen (2005) indicate a high GE in trained cyclists working with high cadence. Gross efficiency is a parameter which may indicate the effectiveness of aerobic work. However, it is not ideal coefficient. As mentioned in the introduction, this coefficient as well as the entire indirect calorimetry has serious limitations. It would seem that the higher GE is, the better it is for the competitor. Meanwhile, GE increases with every increase in work intensity during a progressive test. This is due to the fact that the athlete is already doing more intensive work, but the rate of oxygen uptake which is needed to supply it increases slowly. In this case we have a paradoxical increase of GE. Numerator (labor intensity) increases and the denominator (oxygen consumption) remains temporarily unchanged. It can be assumed that women perform more anaerobic work, as shown during examinations made by the Hopker's team (2010). The problem of anaerobic metabolism and its influence on the calculation of GE is considered in an article by Scott (2005). Reger et al. (2013) found that at low intensities of exercise in untrained people, the corrected gross efficiency in some cases even exceeds the hypothesized values. These claims make the use of GE problematic as a parameter to adequately describe physical abilities.

Many scientists link high GE with better coordination of the contraction and relaxation of the muscles responsible for movement. The use of pressure sensors in the pedals and chain tension gauges in a cycle ergometer allows independent measurements of coordination without determining GE.

The present study has shown that there is a lack of correlation between the gross coefficient and physiological parameters most commonly used to measure physical abilities in cycling. In the examined group there was no correlation of $\mathrm{GE}$ to $\mathrm{VO}_{2} \max , \mathrm{VO}_{2}$ max per $\mathrm{kg}$ of body mass, or $\mathrm{VO}_{2}$ on anaerobic threshold, etc. This result may support the thesis that $\mathrm{GE}$ is not a useful parameter in commonly applied physiological tests measuring the physical abilities of cyclists. On the other hand, it may mean, however, that GE provides new information about examined athletes that is unrelated to the other parameters. However, it is not easy to interpret this information. One would need to collect large amounts of data over a long period of time. Fortunately, it is not difficult to introduce work efficiency as an additional parameter in respiratory gas analyzing software.

\section{Conclusion}

Determining GE at characteristic points of a progressive test could provide new information about the athlete. GE values measured and calculated at the last moments below AT are not correlated with other physiological parameters. It can be concluded that the measurement of GE just below the anaerobic threshold gives new, independent information about the examined athlete. The usefulness of this new information, however, is debatable. 


\section{References}

Abbiss C.R., Laursen P.B. Models to explain fatigue during prolonged endurance cycling. Sports Med. 2005; 35 (10): 865-898.

Beaver W.L., Wasserman K., Whipp B.J. A new method for detecting anaerobic threshold by gas exchange. J Appl Physiol. 1986; 60: 2020-2027.

Cole M., Coleman D., Hopker J., Wiles J. Improved Gross Efficiency during Long Duration Submaximal Cycling Following a Short-term High Carbohydrate Diet. Int J Sports Med. 2014; 35: 265-269.

de Koning J.J., Noordhof D.A., Uitslag T.P., Galiart R.E, Dodge C., Foster C. An Approach to Estimating Gross Efficiency During HighIntensity Exercise. Int J Sports Physiol Perform. 2013; 8, 682-684.

Dumke C.L., McBride J.M., Nieman D.C., Gowin W.D., Utter A.C., McAnulty S.R. Effect of duration and exogenous carbohydrate on gross efficiency during cycling. J Strength Cond Res. 2007; 21 (4): 1214-1219.

Geasser G., Brooks G. Muscular efficiency during steady-rate exercise: effects of speed and work rate. J. Appl. Physiol. 1975; 38 (6): 1132-1139.

Herman I.P. Physics of the Human Body, Springer, Berlin-Heidelberg-New York 2007.

Hopker J., Coleman D., Passfield L., Wiles J. The effect of training volume and intensity on competitive cyclists' efficiency. Appl Physiol Nutr Metab. 2010; 35 (1): 17-22. DOI: 10.1139/H09-124.

Hopker J., Coleman D., Jobson S.A., Passfield L. Inverse Relationship between $\mathrm{VO}_{2}$ max and Gross Efficiency. Int J Sports Med 2012; 33: 789-794.

Leirdal S., Ettema G. The relationship between cadence, pedalling technique and gross efficiency in cycling. Eur J Appl Physiol 2011; 111: 2885-2893.

McArdle W., Katch F., Katch V. Essentials of Exercise Physiology. Lippincott Williams \& Wilkins, 2006.

Moseley L., Achten J., Martin J.C., Jeukendrup A.E. No Differences in Cycling Efficiency Between World-Class and Recreational Cyclist. Int J Sports Med. 2004; 25: 374-379.

Reger M., Peterman J.E., Kram R., Byrnes W.C. Exercise efficiency of low power output cycling. Scand J Med Sci Sports. 2013; 23 (6): 713-721.

Scott Ch.B. Contribution of anaerobic energy expenditure to whole body thermogenesis. Nutr Metab 2005; Jun 15, 2 (1): 14.

Zatoń M., Hebisz R., Hebisz P. Fizjologiczne podstawy treningu w kolarstwie górskim. AWF Wrocław 2011.

Cite this article aS: Borkowski J., Sodolska D., Hebisz R., Zatoń M. The Use of Gross Efficiency Coefficients in Cyclists' Endurance Tests. Central European Journal of Sport Sciences and Medicine. 2015; 12 (4): 35-41. 
